\title{
Analysis of hazard to operator during design process of safe ship power plant
}

T. Kowalewski, M. Sc.

A. Podsiadło, Ph. D.

W. Tarełko, Assoc. Prof.

Gdynia Maritime University

\begin{abstract}
This paper presents comparison of two methods for assessment of hazards to ship power plant operator, used in the preliminary stage of ship power plant design process: the matrix method and that based on fuzzy logic. And, it reports this way results of realization of the research projects [1, 2] financed by Polish Ministry of Science and Higher Education. The assessment of hazard to ship power plant operator, carried out at preliminary design stages meets certain difficulties resulting from that information connected with his safety are scarce or associated with high uncertainty. Therefore fuzzy logic was decided to be used to safety assesment. It was found out that at preliminary design stages application of the fuzzy-logic-based assessment yielded better results as compared with the classic matrix method.
\end{abstract}

Keywords: safety; design process; ship power plant; hazard; fuzzy inference

\section{INTRODUCTION}

Hazard analysis makes it possible to effectively rationalize activities aimed at safety assurance, carried out in the design phase of technical systems. Qualiatitve methods of hazard analysis are commonly used as they are more easily applicable and require much less detailed data than the quantitative ones.

In practice the following occupational hazard assessment methods are usually applied:

- matrix methods in which hazard (risk) value is read from special weighing tables (matrices), e.g. preliminary hazard analysis (PHA), risk matrix acc. the Polish Standard PN 18002 ,

- index methods in which final hazard (risk) value is a more or less complex product of assumed estimating weights, e.g. the Risk Score, Five Steps Method,

- risk graphs where risk value is calculated from an appropriately designed graph, e.g. the Risk Graph,

- other methods with the use of which reviews of control lists are carried out according to elaborated procedures, or detail analyses of production processes and systems, e.g. the Method of Control Lists (CL), ,What- If?” Method.

In the subject-matter literature on occupational hazard assessment, methods based on fuzzy logic are lacking. In this paper are presented results of realization of the research projects $[1,2]$ financed by Polish Ministry of Science and Higher Education. During the research various assessment methods of occupational hazard to ship power plant operator were considered. It was assumed that the subjective risk will be the basis for assessing the occupational hazard. It means that occurrence probability of hazards and quantity of possible consequences resulting from the hazards is assessed with help of experts in the considered area. To achieve such subjective information a special questionnaire was prepared. The information gained from it was used for occupational hazard assessment by using two methods: the matrix method and that based on fuzzy logic.

\section{RESEARCH QUESTIONNAIRE FOR SUBJECTIVE RISK ASSESSING}

To determine subjective information on hazards to ship power plant operator performing operational tasks it was decided to use the output from realization of the first research project of these authors [1]. In its frame were revealed the hazards which greatly impact safety of ship power plant operators. The research questionnaire was aimed at gaining information which makes it possible to estimate operator's hazard level for particular symptoms of the hazards.

For purposes of gaining subjective information from experts and its further assessing the following kinds of hazards to operator were assumed:

- functional ones (connected with function of a device):

- chemical hazard - resulting from factors whose chemical features may endanger health of operator (presonal injury accident or illness), 
- thermal hazard - resulting from possible contact of ship power plant operator with media or/and surfaces of structural elements of various temperature values,

- pressure hazard - resulting from possible contact of ship power plant operator with media or/and surfaces of structural elements being under pressure,

- hazard due to work environment factors- in ship power plant its operator may be exposed to action of factors associated with ship's operation state (noise, vibrations, air parameters and composition, etc).

- mechanical energy hazard - resulting from possible exposure of operator to action of factors generated by an element in its working motion or releasing its elastic deformation,

- electric energy hazard- resulting from possible contact of ship power plant operator with electrically fed machines and devices,

- operational hazards (connected with a kind of realized task):

- hazards resulting from realization of plant operation procedures,

- hazards resulting from the range of the plant operation maintaining,

- hazards resulting from the range of supply procedures,

- hazards resulting from safety state control.

Each of the specified hazards to operator is assessed with respect to the following factors:

- possibility of contact of operator with a given kind of hazard, specified in the questionnaire,

- degree of hazard to operator in the case of direct contact with a given, specified in the questionnaire, kind of hazard.

On the basis of the elaborated questionnaire weighing coefficients for particular kinds of hazard were determined. Owing to that during assessment of operator's safety to account for a different impact of particular kinds of hazards, was possible.

On the basis of the assessment results is gained the information necessary for planning corrective and preventing actions directed to discrepances identified in the process. On the basis of the analysis performed in [1] design phases in which such analysis can be done, were determined. It was found out that the information being at designer's disposal already in the preliminary design stage is sufficient for identification of hazardous areas in ship power plant. Therefore was undertaken an attempt at elaborating, on the basis of preliminary design of ship power plant, such assessment procedure of operator's safety state, on which the following actions could be based:

- choice of the most effective ways for improving safety of operators,

- assessment of degree of improvement of safety of operators.

In order to limit a number of considered areas potentially hazardous to operator the notion of Elementary Hazardous Situation (EHS) was introduced. By using the EHS were defined the situations in which a Service Operation on a given Structural Unit in a given Operating Zone would be realized. The Structural Unit was defined to be a broad-understood technical object, namely, an arbitrary element, part, device, machine and its equipment, installation, which can be considered separately. And, the Service Operation constitutes a set of elementary actions of operator, aimed at realization of a given operating task, e.g. shutting the valve, disconnecting the coupling, dismounting the cover etc. The Operating Zones determine spatial location of a place in which operations are performed on given structural units. The EHSs are analyzed with regard to procedures realized in ship power plant being in given operational states.

\section{RISK ASSESSMENT BY USING RISK MATRIX}

In view of specificity of ship power plant in principle any its place can be more or less hazardous to operators, depending on a kind of realized operating tasks. Therefore it was assumed that scenarios of hazards to operator consist of operational procedures which indicate successively realized operations dealing with given structural units located in given zones of ship power plant. For each distinguished Elementary Hazardous Situation operator's risk is assessed by attributing noxious and dangerous factors, i.e. determined values, to considered hazards. Level of risk to operator realizing a operation within $n$-th procedure, on $m$-th unit located in $k$-th zone of ship power plant, is expressed by means of three indices which account for risk associated with:

- kind of the procedure: $\mathrm{I}_{\mathrm{OF}, \mathrm{m}}^{(\mathrm{n})}$

- function realized by the unit: $\mathrm{I}_{\mathrm{FF}, \mathrm{m}}^{(\mathrm{n})}$,

- functions realized by a set of units located in the neighbourhood of the operator: $I_{R F, k}^{(n)}$.

A high risk associated with hazards due to dangerous and noxious factors induced from the outside is not always connected with high risk resulting from unit's operation and/or a kind of action realized by operator. Therefore risk level of a given elementary hazardous situation is assessed according to the three-point scale (Tab. 1) for each hazard source separately, depending on its relation to respective average value:

$$
\left.\overline{\left(\mathrm{I}_{\mathrm{OF}, \mathrm{m}}^{(\mathrm{n})}\right.}, \overline{\mathrm{I}_{\mathrm{FF}, \mathrm{m}}^{(\mathrm{n})}}, \overline{\mathrm{I}_{\mathrm{RF}, \mathrm{k}}^{(\mathrm{n})}}\right)
$$

calculated for all elementary hazardous situations distinguished in the set of considered procedures.

A result of risk level assessment of elementary hazardous situations as well as relevant procedure is not a sum of estimates but the highest estimate attributed to a given scenario (Tab. 1).

Tab. 1. Assessment of operator's risk level during realization of service operations

\begin{tabular}{|c|c|c|c|c|c|c|}
\hline \multirow{3}{*}{\multicolumn{2}{|c|}{$\begin{array}{l}\text { Operating } \\
\text { procedure }\end{array}$}} & \multicolumn{3}{|c|}{ Risk level of action } & \multirow{3}{*}{ 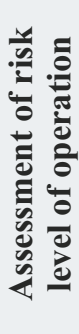 } & \multirow{3}{*}{ 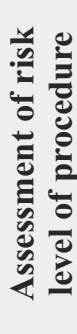 } \\
\hline & & 异 & $\stackrel{\Xi}{\Xi}$ & $\stackrel{\Xi}{0}$ & & \\
\hline & & $\mathrm{I}_{\mathrm{OF}, \mathrm{m}}^{(\mathrm{n})}$ & $\mathrm{I}_{\mathrm{FF}, \mathrm{m}}^{(\mathrm{n})}$ & $\mathrm{I}_{\mathrm{RF}, \mathrm{k}}^{(\mathrm{n})}$ & & \\
\hline$\widehat{\overparen{2}}$ & $a_{1,1}$ & 1 & 1 & 1 & 1 & 3 \\
\hline$\vdots$ & $\cdots$ & $\cdots$ & $\ldots$ & $\ldots$ & $\ldots$ & \\
\hline है & $a_{1, i}$ & 1 & 3 & 1 & 3 & \\
\hline$\approx$ & $\cdots$ & $\cdots$ & $\cdots$ & $\cdots$ & $\cdots$ & \\
\hline - & $a_{1, p 1}$ & 1 & 1 & 2 & 2 & \\
\hline
\end{tabular}


Tab. 2. Assessment of operator's risk range for operating procedures

\begin{tabular}{|c|c|c|c|c|}
\hline \multirow[t]{2}{*}{ 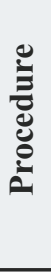 } & 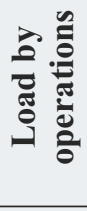 & 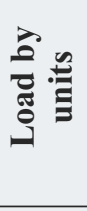 & 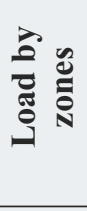 & \multirow[t]{2}{*}{ 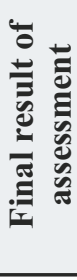 } \\
\hline & $\mathrm{I}_{\mathrm{A}}^{(\mathrm{n})}$ & $\mathrm{I}_{\mathrm{U}}^{(\mathrm{n})}$ & $\mathrm{I}_{\mathrm{R}}^{(\mathrm{n})}$ & \\
\hline $\mathrm{P}_{1}$ & 2 & 3 & 1 & 6 \\
\hline$\cdots$ & $\cdots$ & $\cdots$ & $\cdots$ & $\cdots$ \\
\hline$P_{p}$ & 3 & 3 & 2 & 8 \\
\hline
\end{tabular}

A large value of estimate of potential risk to operator during realization of $n$-th procedure may result from a different number of realized operations which may deal with one or a greater number of units located in one or many zones of ship power plant. Therefore to assess range of operator's risk it is proposed to determine, for each procedure, values of the indices of loading by operations, $\mathrm{I}_{\mathrm{A}}^{(\mathrm{n})}$, procedures, $\mathrm{I}_{\mathrm{U}}^{(\mathrm{n})}$, and zones, $\mathrm{I}_{\mathrm{R}}^{(\mathrm{n})}$.

A high level of hazard due to dangerous and noxious factors resulting from number of realized operations is not always connected with a high level of hazard associated with number of units and zones of ship power plant. Therefore risk range of a given operating procedure is proposed to be assessed according to the three-point scale (Tab. 1) for each kind of hazard separately, depending on its relation to respective average value calculated for a set of considered procedures.

Final result of assessment for a given procedure is a sum of estimates for loading by operations, units and zones (Tab. 2).

Results of assessment of level and range of operator's risk constitute the basis for making decisions about which hazard scenarios (operating procedures) should be subjected to moderating strategies (Tab. 3).

Tab. 3. Summary of results of assessment of operator's risk during realization of operating procedure

\begin{tabular}{|c|c|c|c|}
\hline \multirow{2}{*}{$\begin{array}{c}\text { Risk } \\
\text { level of } \\
\text { operating } \\
\text { procedure }\end{array}$} & \multicolumn{3}{|c|}{ Risk range of operating procedure } \\
\cline { 2 - 4 } & 3 & $4-6$ & $7-9$ \\
\hline 3 & $\mathbf{R}$ & $\mathbf{Z}$ & $\mathbf{Z}$ \\
\hline 2 & $\mathbf{U}$ & $\mathbf{R}$ & $\mathbf{Z}$ \\
\hline 1 & $\mathbf{U}$ & $\mathbf{U}$ & $\mathbf{R}$ \\
\hline
\end{tabular}

The result $\mathbf{Z}$ - 'moderate' - stands for necessity of undertaking corrective actions to lower the risk to a permissible level (average or lower one).

The result $\mathbf{R}$ - 'consider' - stands for that to plan actions aimed at lowering the risk is advisable.

The result $\mathbf{U}$ - 'substantiate' - stands for that it is advisable to consider if further lowering the risk level is possible or to ensure that the risk would maintain on the same level at least.

As already mentioned, for each distinguished Elementary Hazardous Situation operator's risk is assessed by attributing noxious and endangering factors, i.e.definite values to input variables. On the basis of the questionnaire tests performed with a group of ship engineers, to every distinguished input variables a constant weighing coefficient was attributed. Moreover, for every distinguished state (symptom) of every variable, assessment coefficients of risk level and of frequency of its occurence, were determined.
The product of occurrence frequency of a given hazard - inducing event and its consequences is assumed to be a risk measure. A risk estimate category (risk levels) is read from a risk matrix. Such matrix makes it possible to perform, for every distinguished factor (either functional or operational), the following:

- to attribute risk estimate due to action of a distinguished factor, expressed by the integer numbers: 5, 4, 3, 2 and 1 , as well as verbally: very high risk, high risk, medium risk, low risk, very low risk,

- to apply the estimations to risk assessment of:

- an Elementary Hazardous Situation (EHS),

- a set of EHSs considered from a given point of view, e.g. risk assessment for a given structural unit (which service operations are performed by a given operator and which technical objects are in his surroundings).

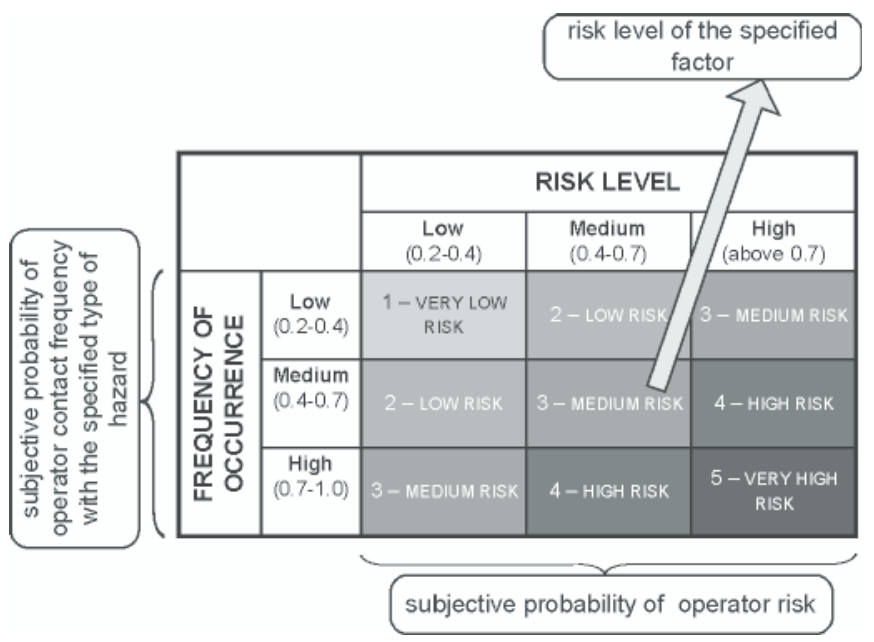

Fig. 1. The hazard-induced risk assessment matrix

In general, risk is defined as the product of occurrence frequency of a given hazard - and probable losses resulting from an incurred damage. On this basis and the preformed questionnaire tests the hazard-induced risk assessment matrix was elaborated (Fig. 1).

\section{RISK ASSESSMENT OF ELEMENTARY HAZARDOUS SITUATION BY USING FUZZY LOGIC}

The first attempt to making use of fuzzy logic to risk assessment for ship power plant operator was described in [3]. Since the time the method has been subjected to certain modifications. The assessing of operator's risk has been so far based only on determining hazards to safety of operator during realization of given operations. In order to more reliably determine possible hazards, information associated with frequency of operator's contact with selected kinds of hazards, has been taken into account. Additionally, forms of memebership functions of particular fuzzy sets have been modified.

Data achieved from the questionnaires were applied to building fuzzy sets both in discrete and continuous domain. Sets in the continuous domain were used to hazards due to temperature and pressure. Values obtained from the questionnaires for the hazards were linearly approximated and normalized to achieve sets of a triangular or trapezoidal form. For the remaining hazards the sets were expressed in the discrete form because of a limited number of elements in the space of consideration, $X$. The example discrete memebership functions of degree of hazard to operator in case of his direct contact with a given kind of hazard, are presented in Fig. 2. The continuous memebership functions 
Parameters of electrical energy - possibility of contact

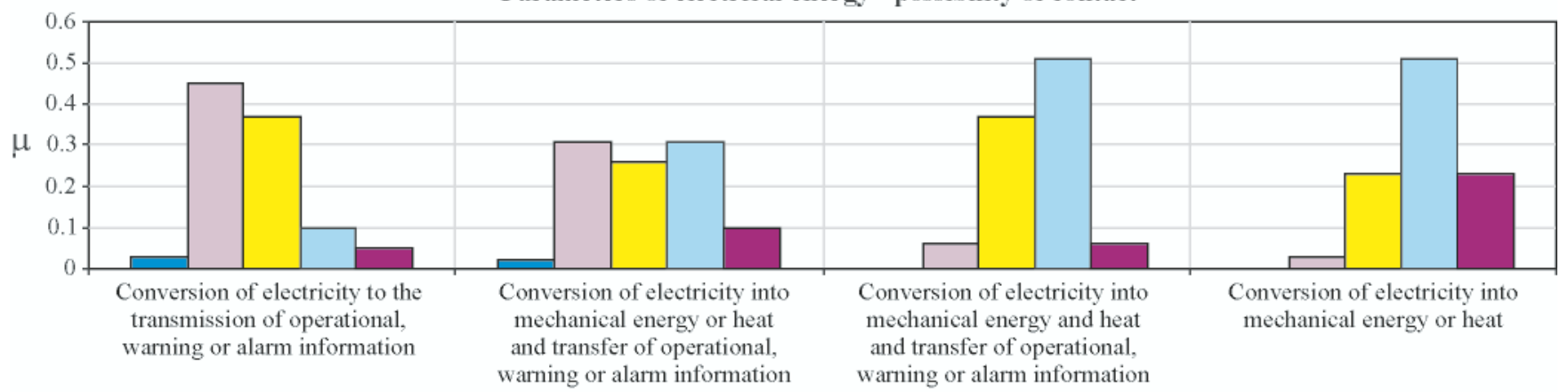

Electricity utilization way

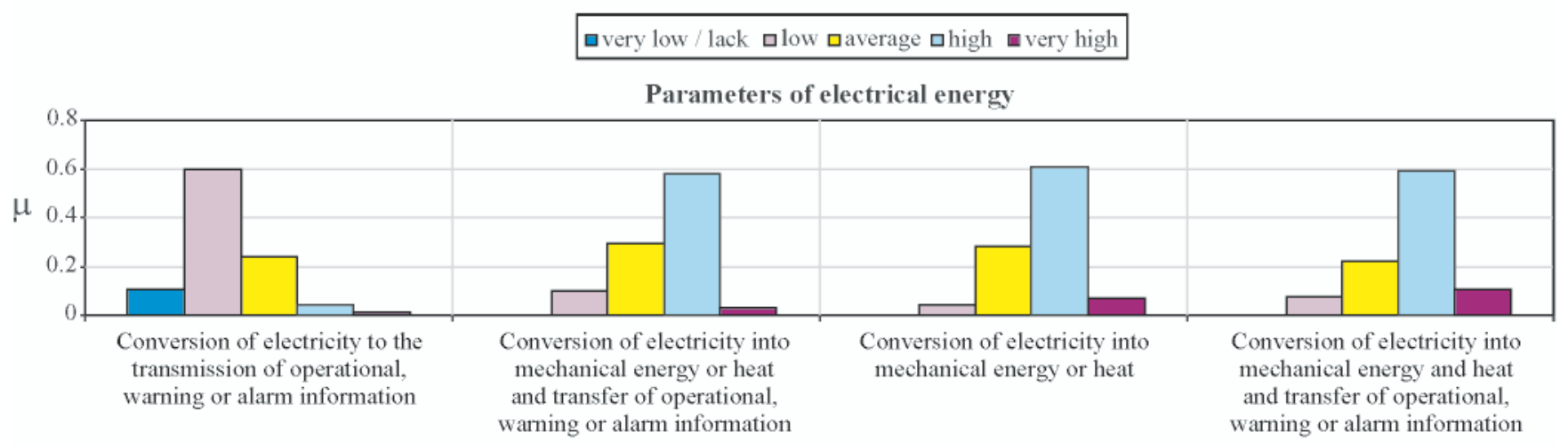

Electricity utilization way

Fig. 2. Discrete memebership functions of degree of electrical hazard to operator

for fuzzy sets are shown in Fig. 3. To ensure comparability of risk assessments for every Elementary Hazardous Situation with the use of fuzzy logic, the linearly ordered range, from 0 to 5.0, of resulting hazard to operator, was assumed (Fig. 4).

The assessing of risk resulting from Elementary Hazardous Situation is made by using fuzzy inference.

It consists in:

- determination of:

- degree of hazard to operator in case of his direct contact with particular kinds of hazard,

- possibility of contact of operator with particular kinds of hazard,

- calculation of an aggregated assessment index of hazard level induced by an Elementary Hazardous Situation (EHS),

- the carrying-out of defuzzification to make it possible to assess risk of the EHS.

Assessments of degree of hazard to operator as well as possibility of his contact with particular kinds of hazard are obtained from memebership functions on the basis of a set of rules. The rules are of a fuzzy matrix form. The example matrix of rules, which makes it possible to determine level of pressure hazard to operator is shown in Fig. 5.

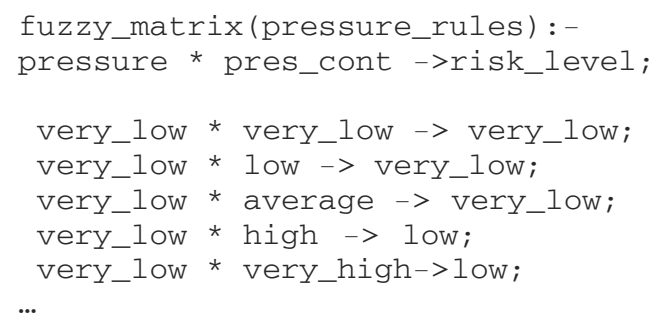

Fig. 5. Matrix of rules for pressure hazard
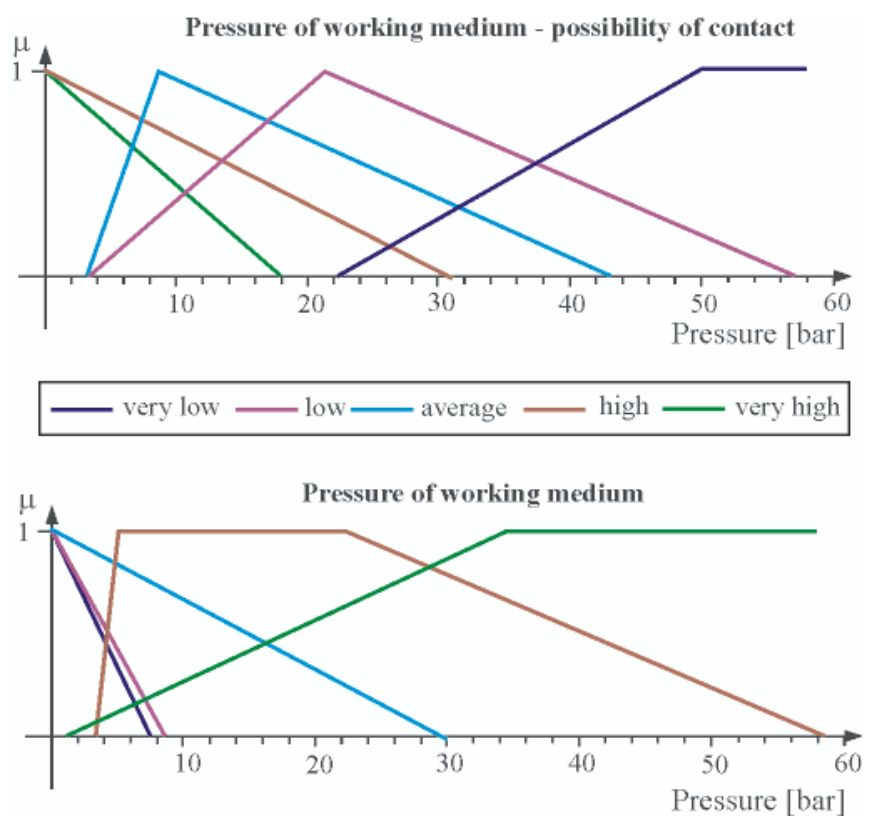

Fig. 3. Memebership functions which determine pressure hazard to operator

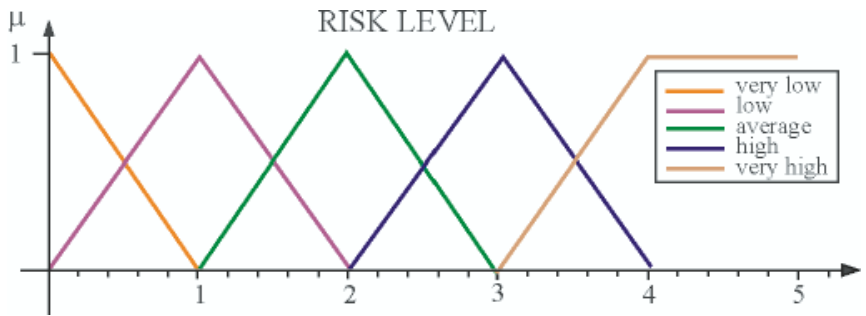

Fig. 4. Resulting fuzzy sets which determine degree of hazard (risk level) to operator 
The rules contained in it can be iterpreted as follows: "If pressure hazard level (in case of direct contact) is very low and possibility of contact (with the symptom) is very low then the level of the hazard to operator is very low".

The resulting values which determine level of hazard to operator are achieved as a result of fuzzy inference according to Mamdani model. During the process the matrix of rules is searched in order to determine degree of their activation. Only the rules concerning fuzzy sets dealing with the assumed input quantities, are taken into account. Each of the rules generates a resulting fuzzy set of a definite height. In the next phase the sets are summed-up. The so - obtained fuzzy set makes it possible to determine finally a level of hazard to operator.

To form such a matrix at twelve input variables is very difficult. Therefore the variables were grouped into six pairs composed of hazard levels (in case of direct contact) and possibility of contact with a given kind of hazard. For each of the pairs separate resulting fuzzy sets are determined in the fuzzy inference process. In the final phase of the inference a 'sharp' resulting value is determined in the defuzzification process on the basis of sum of the sets.

To exemplify the fuzzy inference an example assessment of hazard during replacement of heavy oil transporting pump is considered. The task is realized by using a fuzzy inference mechanism available in the programming language PROLOG LPA. values:

E.g. if the following symptoms are assumed initial

- hazard due to work environment factors: manoeuvres,

- chemical hazard: fuel (heavy oil),

- pressure hazard:12.5 bar

- thermal hazard: $150^{\circ} \mathrm{C}$

- mechanical energy hazard: rotating element in permanent or periodical motion,

- electrical energy hazard - electrical energy is converted to mechanical or thermal one, then the resulting risk level amounts to 2.2 .

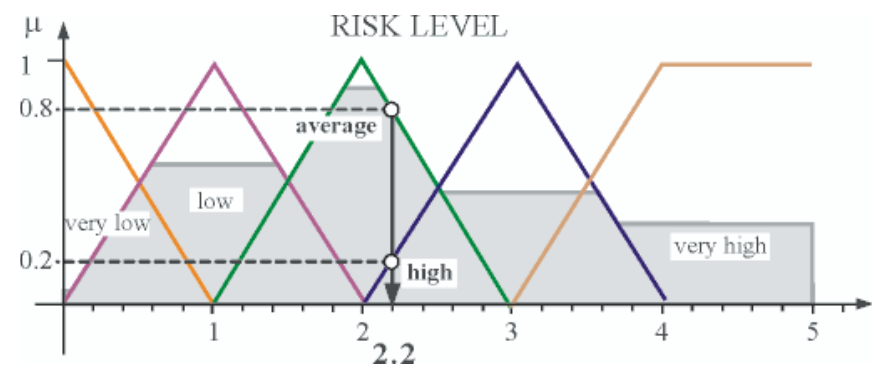

Fig. 6. Final value of risk assessment of Elementary Hazardous Situation after defuzzification

The obtained value is equivalent to the average risk level of $\mu=0.8$ and the high risk level of $\mu=0.2$ (Fig. 6).

\section{CONCLUSIONS}

On the basis of the results obtained in the course of the performed investigations it can be stated that the risk assessment of elementary hazardous situation with the use of the risk matrix shows certain disadvantages among which the following, a.o., can be numbered:

- the additive method for determining assessment index of degree of hazard to operator, that causes the linear ordering of potential impact of particular symptoms of particular variables, and not quite adequately reflects real impact of particular symptoms of distinguished factors on inducing hazard to operator,

- the necessity of performing assessment of all Hazardous Zones covered by realized operating procedure, even in the case when the zones can not in reality produce any potential hazard.

In the case of the assessment method of risk resulting from Elementary Hazardous Situation, based on fuzzy logic, it is possible to fulfil a very important postulate, namely to ensure comparability of operator's hazard level in case of all Elementary Hazardous Situations.

Moreover, there is not necessary to determine weighing coefficients for particular functional factors, as this is the case when assessing risk from Elementary Hazardous Situation by using the risk matrix. It results from that the assessment is performed by user of the system (ship power plant designer responsible for accounting for operator's safety during design process), but not its designer. It means that assessment of level of a hazard to operator, resulting from possible action of functional factors, is performed during the design process from the point of view of harmfulness of possible effects to operator. The user of the system, considering a set of states of a given functional factor, assesses harmfulness of effects to operator not comparing them with gravity of effects resulting from other functional factors.

It can be stated that fuzzy logic offers wide possibilities in analyzing safety of ship power plant operator, especially in the initial design stages where information associated with his safety are very scarce or uncertain.

In contrast to the classical solutions, the method of operator's risk level assessment with the use of fuzzy rules, reflects qualitative aspects of human knowledge in a more realistic way, and the inference process itself does not require making any quantitative analyzes.

\section{BIBLIOGRAPHY}

1. Tarełko W. et al.: Antropotechnical assumptions for the designing of safe technical objects - the content-related report (in Polish). Report on realization of the research project No. 8T07C 01120 financed by Polish Scientific Resarch Commitee (KBN). Bulletin No. 1. KPT. Gdynia Maritime University, Gdynia 2004

2. Tarełko W. et al.: A method of designing safety of operators of complex technical

objects - the content-related report (in Polish). Report on realization of the research project No. 4T07B02529 financed by Polish Scientific Resarch Commitee (KBN). Bulletin No. 1. KPT. Gdynia Maritime University, Gdynia 2009

3. Kowalewski T., Podsiadło A., Tarełko W.: Application of fuzzy inference to assessment of degree of hazard to ship power plant operator. Polish Maritime Research, No. 3(53), vol. 14, Gdańsk 2007

T. Kowalewski, M. Sc.

A.Podsiadło, Ph. D.

W.Tarełko, Assoc. Prof.

Faculty of Marine Engineering,

Gdynia Maritime University

Morska 83

81-225 Gdynia, POLAND

e-mail: tar@am.gdynia.pl 